\title{
The Right of Children to Free and Compulsory Education Act (RTE): A Case Study of its Functioning in Delhi, Uttar Pradesh and Punjab
}

\author{
Meera Nath Sarin
}

Lecturer, Institution Affiliated with University College London Institute of Education

Corresponding author: m.sarin.14@ucl.ac.uk

\author{
Received: $23-08-2020$ \\ Revised: $15-10-2020$ \\ Accepted: 25-11-2020
}

\begin{abstract}
This article presents the findings from case study research that was conducted into how the child-centred education policy incorporated within RTE, enacted in India in 2009, is functioning. Interviews were conducted with teachers who worked at different schools in New Delhi, Noida (Uttar Pradesh) and Amritsar (Punjab) with the analytical aim of gaining insights into how the RTE provisions are functioning from their perspectives based on their daily teaching practice. The findings show that the functioning of seven out of eight of the child-centred education provisions of RTE as well as the new role of the Indian teacher as 'facilitator' is problematic.
\end{abstract}

Keywords: RTE, child-centred policy, functioning, comprehensive and continuous evaluation, nodetention policy, education for all

The Right of Children to Free and Compulsory Education Act (RTE) was passed in India in August 2009 by a Congress-led coalition government and came into force in April 2010. It constitutes legislation aimed at achieving universal elementary education (UEE) in India, a state objective since Independence in 1947, which has yet to be achieved. This aim is also supported by Samagra Shiksha, which supercedes Sarva Shiksha Abhiyan, India's education for all programme.

RTE provides for 'free and compulsory education' at primary and upper primary levels in state (government) schools in India. Its overall provision is that:

Every child of the age of six to fourteen years shall have a right to free and compulsory education in a neighbourhood school till completion of elementary education.

(Government of India, 2009: p. 1).
The trajectory of the term 'free and compulsory education' was traced as part of the overall research underlying this article to establish the genesis of RTE. This revealed that it constitutes a discourse for the provision, either implicitly or explicitly, of UEE in India and that this discourse has been connected to efforts to universalise education in India for more than a century. The discourse began with the plea in 1906 before the Imperial Legislative Council of Gopal Gokhale - an eminent contemporary social reformer - for the introduction of 'free and compulsory education' and continued after Independence as an integral part of the national education policy documents of 1968, and 1986 as amended in 1992, and which now continues with

\footnotetext{
How to cite this article: Sarin, M.N. (2020). The Right of Children to Free and Compulsory Education Act (RTE): A Case Study of its Functioning in Delhi, Uttar Pradesh and Punjab. Educational Quest: An Int. J. Edu. Appl. Soc. Sci., 11(4): 149-160.
}

Source of Support: None; Conflict of Interest: None

(9) 
the constitutional amendment of 2002 that laid the foundation for the legislation that constitutes RTE - Article 21A - and RTE. The Legislation constitutes a continuation of efforts to achieve UEE in India within this discourse.

The tracing of the trajectory of 'free and compulsory education' also revealed that RTE is significant as the first national legislation in three areas: for education in India since Independence in 1947, for achieving UEE and for the provision of child-centred education. The latter is a continuation of national policy objectives for its provision previously contained in the policy documents of 1966, 1968 and 1986 as modified in 1992, some elements of which are precursors to provisions of RTE.

This article is based on a qualitative case study conducted for a Doctorate in Education degree that investigated how the child-centred approach incorporated within RTE is conceptualised and how it is functioning as a policy. This research was conducted prior to the changes that were made to two of the child-centred education provisions by the current Bharatiya Janata Party (BJP) government through an Amendment of January 2019. The article presents the findings from the investigation into how RTE's child-centred education policy is functioning, which constitutes a follow-up to earlier research of 2002 into how RTE and its related reforms were being implemented, two years after RTE came into force (Sarin, 2015). The provisions of the Legislation and how the child-centred education policy is conceptualised are first set out, followed by a presentation of the findings of a review of literature that investigates how RTE is functioning. Features of the research conducted for this case study as well as its findings are then presented.

\section{The child-centred education provisions of RTE}

The provisions for child-centred education are contained within Chapter V of RTE, as follows:

\section{CURRICULUM AND COMPLETION OF ELEMENTARY EDUCATION}

29. (1) The curriculum and the evaluation procedure for elementary education shall be laid down by an academic authority to be specified by the appropriate Government, by notification.
(2) The academic authority, while laying down the curriculum and the evaluation procedure under sub-section (1), shall take into consideration the following, namely:-

(a) conformity with the values enshrined in the constitution;

(b) all-round development of the child;

(c) building up the child's knowledge, potentiality and talent;

(d) development of physical and mental abilities to the fullest extent;

(e) learning through activities, discovery and exploration in a child-friendly and childcentred manner;

(f) medium of instructions shall, as far as practicable, be in child's mother tongue;

(g) making the child free of fear, trauma and anxiety and helping the child to express views freely;

(h) comprehensive and continuous evaluation of child's understanding of knowledge and his or her ability to apply the same.

30. (1) No child shall be required to pass any Board examination till completion of elementary education.

(2) Every child completing his elementary education shall be awarded a certificate, in such form and in such manner, as may be prescribed.

(Government of India, 2009: p. 9)

The policy document that has supported RTE, Sarva Shiksha Abhiyan: Framework for Implementation (SSA Framework), clarifies that 'curriculum' refers to all aspects of education. It does not provide a theoretical rationale for the child-centred education provisions of RTE. The explanation it does provide conceptualises the provisions as comprising democratic aims and ideals and a democratic form of assessment and learning. This clarification is limited to provisions (e) to (h), with a more comprehensive explanation being provided only for provision $h$ ).

A theoretical framework was constructed for the Study to facilitate conceptual understanding of the child-centred policy and to provide a benchmark for the interpretation of how the policy is functioning, details of which are provided below.

Analysis of the RTE provisions in relation to this 
framework determined that provisions (a) to (d) and $(\mathrm{g})$ to $(\mathrm{h})$ can be conceptualised as a democratic form of education and that provision (e) can be conceptualised as a form of experiential learning. This analysis and conceptualisation form the foundation for the conclusions about the functioning of the policy that are presented.

\section{How child-centred education is conceptualised within RTE}

As stated above, RTE provisions (e) to (h) are conceptualised in SSA Framework in terms of democratic aims and ideals. The document frames provision (e) as a 'core component of quality learning', teacher-dominated pedagogy as undesirable and reiterates the call of The National Curriculum Framework of 2005 (this is the prevailing policy document and is planned for revision at the end of 2020) for employing 'critical pedagogy' as part of a constructivist approach to teaching and learning so that learners can understand the world around them and because it "...... foregrounds questions of inequality and justice and enables learners to undertake transformative action" (Government of India, 2011: p. 64). Provision (f) is defined as an 'equity issue' because "The biggest problem faced by tribal children is that of language. ...... inclusion of tribal children hinges crucially on the language issue" (Government of India, 2011: p. 35). The document clarifies the issue as the historical exclusion of tribal children from education and their likelihood to drop out of school because of language differences between school and home. Provision ( $\mathrm{g}$ ) is framed as an 'essential component of quality education' and is specified as working in conjunction with the democratic aims of clause IV.17(1), which prohibits corporal punishment or mental harassment with the aim of providing "...... a democratic 'learning environment' in the form of a nurturing school, and not a 'correctional centre' (Government of India, 2011: p. 80-81).

The rationale provided for provision $h$ ) as a form of assessment is contained in the following two statements:

The RTE Act calls for setting up of such continuous and comprehensive system of evaluation that releases the child from the fear and trauma of failure, but enables the teacher to pay individual attention to children's learning and performance.

(Government of India, 2011: p. 81). and

Research shows that the more competitive a test the more it actually selects social advantage, whereas collaborative and non-threatening assessment of children's progress leads to better learning of all. This is why the RTE Act (Section 13) has banned any kind of screening procedure for children and parents at the time of admission, has barred detention or expulsion of a child, and even disallowed the conduct of Board Examinations till a child completes elementary schooling (class VIII). This is to give the child adequate time to develop her learning and understanding fully through an enabling educational environment, and through a system of continuous and comprehensive assessment which enhances learning.

(Government of India, 2011: p. 57).

The other RTE provisions referred to in this paragraph are as follows:

IV.13.(1) No school or person shall, while admitting a child, collect any capitation fee and subject the child or his or her parents or guardian to any screening procedure

IV.16. No child admitted in a school shall be held back in any class or expelled from school till the completion of elementary education

30.(1) No child shall be required to pass any Board examination till completion of elementary education

SSA Framework links IV.16. above, which prohibits the holding back of students until the completion of primary school in grade eight and is referred to as the 'no- detention policy' (NDP), to RTE provision (h) through its statement that 'no detention' "... implies putting in place a continuous and comprehensive procedure of child assessment and records" (Government of India, 2011: p. 81).

The aim of 'comprehensive and continuous evaluation' (CCE), as stated in SSA Framework, is to replace the inherently competitive and stressful system of examinations at the end of every school year - in which evaluation is seen a means of 'judging and passing a verdict' - with continuous assessment throughout the year by means of assignments and classroom activities. The assessment criteria include developmental as well as academic aspects, relating to the students' health, 
physical fitness, self-image, sensibilities, social skills and abilities in arts and crafts. Teachers are to provide progress reports to children and parents in the form of 'report cards' that make qualitative statements about the student's progress in academic and developmental areas and are also intended to provide learners with feedback and standards to achieve. CCE is also aimed at enabling teachers to pay individual attention to students' learning and performance. The assessment objectives of CCE and the requirements of teachers in relation to it are set out in detail below:

\section{COMPREHENSIVE AND CONTINUOUS EVALUATION \\ The objectives of CCE assessment (Government of India, 2011: p. 66)}

1. To give learners and teachers a sense of what is being learnt and how, in order to improve learning and teaching practices

2. To show what progress the child has made with respect to her own performance over time and not compare one child with another

3. Must enhance the student's motivation, which is crucial for any learning

4. Treat assessment as an integral part of teaching and learning, through observations of children and maintaining records of their work done in a portfolio, rather than as a judgement

Teachers are required to do the following for 'comprehensive evaluation':

(Government of India, 2011: p. 68)

1. View the child from a holistic perspective rather than just a learner of different school subjects: to perceive aspects such as the child's health, self image, and sensibilities in the context of development and growth.

2. Make every effort, through interaction and engagement, to observe and understand the child's own nature. It is important that the teacher does not judge the child's nature, but should notice the inherent potential of the child in the context of his/her own nature.

Teachers are required to do the following for 'continuous evaluation':

(Government of India, 2011: p. 68)

The teacher's work should be continuously guided by the child's response and participation in lassroom activities, so evaluation should be seen as a process whereby the teacher can learn about the child in order to teach better.

\section{The role of the teacher}

The role of the Indian teacher is also conceptualised in terms of democratic aims and ideals. The teacher is a 'facilitator', a role that is described as representing a transformation from the traditional one, a 'shift in the understanding of teaching and learning' and a move from 'teacher-directed' to 'learner-centric' learning (Government of India, 2011: p. 75) and is defined as follows:

SSA visualises teachers as a capable facilitator, who motivates children to construct their own knowledge. The teacher should be aware about progressive pedagogy and must know the nature and experiences of children from various social and cultural backgrounds. Moreover, RTE requires that teachers should be committed to equity and social justice, aware about child entitlements and convinced that all children can learn well if provided education of equitable quality.

(Government of India, 2011: p. 69-70).

\section{Literature review}

An emergent body of literature on the implementation of RTE consisting of twelve articles was reviewed. They all focussed on issues to do with the functioning of 'comprehensive and continuous evaluation' (CCE), provision V.29.(1) (h) of RTE. The findings reported in these studies indicate that while teachers found some aspects of the new evaluation system to be positive, they found it to be far more problematic than beneficial. Teachers reported six main problem areas with CCE: lack of training, difficulty assessing, maintaining the student report cards, poor student motivation, lack of infrastructure and resources and increased teacher workload. The particular difficulties reported are presented below:

Lack of or inadequate training was a major issue for teachers (Saluja, 2016; Kothari and Thomas, 2012; Kumar and Kumar, 2015; Ashita, 2013; Singhal, 2012; Pazhanimurugan et al. 2015; Thakur, 2016). They also found that the guidelines and manuals they had been provided with were unhelpful (Kothari and Thomas, 2012; Ashita, 2013; Saluja, 2016) and lacked the necessary information that would provide clarity on how to properly implement CCE (Kothari and Thomas, 2012).

Teachers found it difficult to assess according to CCE requirements. There were four main problem 
areas: they reported that although CCE was intended to reduce their burden, they actually found that as a form of assessment it was a difficult and time-consuming task that set unrealistic expectations (Sethi and Muddgal, 2017). Teachers were unclear on how to actually assess students (Kothari and Thomas, 2012; Ashita, 2013) and were not sure how to account for individual differences in ability and talent (Kothari and Thomas, 2012). They found it very difficult to evaluate the various practical projects that students are required to take part in and thought this was a major limitation of the training they had received; they would assign grades to students based on certain skills, but subsequently might find it difficult to explain why particular grades had been assigned (Saluja, 2016). Finally, Mishra and Mallik (2014) and Thakur (2016) reported that teachers could not properly evaluate either curricular activities or the socio-personal qualities of learners due to lack of training, shortage of teachers, inadequate supporting infrastructure, paucity of time and heavy workload. They also found it difficult to assess the non-academic criteria because of their previous observations and personal relationship with the student, and also because the behaviour of an individual student can differ.

Implementing the student report cards as required was problematic for teachers, for various reasons: they were very time consuming to fill in and maintain (Ashita, 2013; Kumar and Kumar, 2015; Saluja, 2016; Thakur, 2016) and teachers thought these activities wasted a lot of time (Mishra and Mallik, 2014). They might also have to first be kept on class registers and then copied to the report cards, which took a great deal of time and effort (Saluja, 2016). Teachers spent considerable time converting students' marks into grades in accordance with the CCE formats rather than teaching; they could seldom teach remedially in accordance with the continuous assessment results or provide the required descriptive feedback; and only fifteen per cent of teachers said that they maintained records of student performance on a daily basis (Saluja, 2016). Having to maintain these records during class time was also problematic (Ashita, 2013; Sethi and Muddgal, 2017) and the resultant loss of teaching time led to the neglect of daily classroom assessment and other teaching activities (Ashita, 2013). There were also administration-related issues: teachers might receive the report cards in the middle of the term, which made it difficult to evaluate students, and the reports were not properly maintained Saluja (2016).

Lack of student motivation to learn made it difficult for teachers to assess in accordance with CCE (Singhal, 2012; Ashita, 2013; Kumar and Kumar, 2015; Saluja, 2016; Thakur, 2016) and students not being serious about studying was a serious concern for teachers (Singhal, 2012; Kumar and Kumar, 2015; Pazhanimurugan et al. 2015). In one study, approximately forty per cent of teachers were in favour of re-introducing the examination system because they thought that would encourage students to take their studies seriously and work harder, whereas they currently had no fear of examinations or of failing (Saluja, 2016). Teachers thought that students viewed the work for CCE as simply a way of getting marks or grades; they purchase material from the market or download it from the Internet without even reading it (Ashita, 2013). They also thought students did not take the evaluation seriously since they know they will pass without making an effort (Thakur, 2016). Student absenteeism was also problematic for implementing CCE (Ashita, 2013; Saluja, 2016), as well as irregularity in school attendance (Panda, 2014; Sethi and Muddgal, 2017).

Lack of infrastructure and resources, including a high teacher-pupil ratio, added to the difficulties that teachers experienced with implementing CCE (Singhal, 2012; Ashita, 2013; Kumar and Kumar, 2015; Mishra and Mallik, 2014; Pazhanimurugan et al. 2015; Thakur, 2016). The high teacher-pupil ratio typical of state schools in India, which can range from 50-90 students per class, made it significantly difficult for them to assess students as required (Kothari and Thomas, 2012; Singhal, 2012; Ashita, 2013; Kumar and Kumar, 2015; Mishra and Mallik, 2014; Panda, 2014; Pazhanimurugan et al. 2015; Thakur, 2016; Saluja, 2016; Sethi and Muddgal, 2017). Behaviour management became a problem, which caused disturbance to nearby classes; teachers thought this was mainly due to the high number of students in the class and that having fewer students would solve the problem (Kothari and Thomas, 2012). Approximately twenty-five per cent of teachers reported that they were involved in multi-grade teaching and that it was almost 
impossible to effectively assess all the students of two or more classes simultaneously; teachers also found it difficult to pay individual attention to each student and to teach the weak students remedially (Saluja, 2016).

CCE has increased the workload of teachers: (Singhal, 2012; Kumar and Kumar, 2015; Panda, 2014; Mishra and Mallik, 2014; Pazhanimurugan et al. 2015; Saluja, 2016; Thakur, 2016), which includes an increase in paperwork (Basu and Debnath, 2016). This results in three issues: firstly, time is taken away from learning (Srinivasan, 2015). Secondly, teachers reported that the increased volume of work has affected their teaching (Thakur, 2016). They had insufficient time to conduct all the activities recommended under CCE or to evaluate all the students on all aspects simultaneously (Saluja, 2016) and they lacked time to explain conceptual issues or to provide remedial assistance to students (Srinivasan, 2015). They found it difficult to complete the syllabus on time (Kothari and Thomas, 2012; Saluja, 2016; Sethi and Muddgal, 2017) and felt they were at times unable to do proper justice to CCE (Saluja, 2016; Kothari and Thomas, 2012). Thirdly, teachers reported that the increased volume of work prevented them from implementing CCE properly (Pazhanimurugan et al. 2015; Singhal, 2012) and they were unable to assess all students (Sethi and Muddgal, 2017).

\section{The research and its findings}

\section{The starting points}

The provisions for child-centred education within RTE constitute an approach to educating children that has its philosophical and historical antecedents in what has come to be known as 'child-centred' education, an approach which has its origins in the philosophical thought of the Enlightenment of $18^{\text {th }}$ century Western Europe and an ideological reach that has spanned internationally in various forms since then. Child-centred education became popular in India as it spread internationally where it developed pedagogically from the early twentieth century through the work of proponents such as Mahatma Gandhi and Rabindranath Tagore. Currently, the policy incorporated within RTE can be situated in the international policy context of learner-centred education (LCE), through
India's involvement as signatory to the Incheon Declaration and Framework for Action adopted in 2015 to achieve education for all by 2030 through its 'Sustainable Development Goal 4' - which states that education requires "learner-centred, active and collaborative pedagogical approaches" as part of its focus on quality and learning to achieve this goal (UNESCO, 2016: p. 33) - and also because there are pedagogical commonalities between LCE and childcentred education approaches.

An examination of the historical and policy contexts of RTE, which was conducted as part of the overall research,showed that the Indian policy has historical roots in national education policy that can be traced back to 1966. Also, as stated earlier, RTE is rooted in its own discourse, that of 'free and compulsory education'. The consequent assertion that the childcentred education policy of RTE can be understood and analysed separately from its international policy context formed a starting point of the investigation and informed the analysis of the empirical research conducted.

A second starting point was the assertion that the Indian child-centred education policy - which consists of the child-centred education provisions of RTE and the new ascribed role of the Indian teacher as 'facilitator - is considered to be sound because it is supported by the theoretical framework of the Study. Details of this framework are provided below. This assertion provided a starting point for the analysis of how the policy was functioning.

\section{METHODOLOGY}

The time frame of the research project was October 2014 to August 2018. The fieldwork in India was conducted from July to September 2015. A qualitative approach informed by an Interpretivist perspective was taken in the form of an 'intrinsic' case study (Stake, 1995, 2005) where the epistemological question consists of what can be learned about the single case (Stake, 2005). The related research aim was to investigate how the child-centred education approach incorporated within RTE is conceptualised and how it is functioning as a policy. This article presents the findings from the latter part of the investigation, which was conducted by interviewing Indian teachers with the analytical aim of gaining insights into how the policy is functioning from their 
perspectives based on their daily teaching practice. The research with teachers also incorporated an 'insider' researcher perspective - whilst recognising that the dichotomy of 'insider-outsider' research is contested - based on the researcher's personal biography and existing knowledge of the research area.

Semi-structured interviews of approximately an hour and a half's duration were conducted with twenty-one teachers - eighteen female and three male - in Hindi, Punjabi and English, either in a home or at a school. The teachers worked at different schools in New Delhi and Noida, Uttar Pradesh as well as at two schools in Amritsar, Punjab and taught a range of subjects to mostly $11^{\text {th }}$ and $12^{\text {th }}$ grade students. All names, including those of the schools, were kept anonymous and no photographs were taken as part of maintaining the ethical foundation of the research.

The data derived from the interviews consisted of transcriptions in English of recordings of the interviews, with the Hindi and Punjabi content having been translated. The data constituted 'representations' of the teachers' experiences (Silverman, 2006) and originated from the interview questions which were drawn either specifically or broadly from the policy in relation to the teachers' daily practice, thereby constituting the responses of teachers about the challenges they experienced with the policy in their day-to-day teaching practice. This foundation constituted the 'connective thread' between the experiences of the teachers (Seidman, 2006) across the various schools in their different locations, thereby enabling a unification of the data.

An innovative feature of the research was the construction of an original theoretical framework to facilitate conceptual understanding of the childcentred policy and to provide a benchmark for the interpretation of how the policy is functioning. The concepts of 'Democracy', 'Experiential Learning' and 'Teacher as Facilitator' - drawn from the original work of Jean-Jacques Rousseau and John Dewey-constituted the foundation of the theoretical framework. Definitions of these concepts based on the authors' original work were formulated to construct the theoretical framework. This was employed to interpret the data obtained from the interviews with Indian teachers and to provide a benchmark for the delivery of child- centred education to determine how the policy is functioning.

A thematic analysis was conducted as a first step of the data analysis. This led to the identification of issues to do with the functioning of the RTE provisions. These findings were not differentiated according to the teachers' location and represent the views of the vast majority of the teachers interviewed. They consequently represent the main issues the teachers were concerned about and found to be most challenging in their daily practice as a single group.

\section{The main issues the teachers identified}

While a few teachers had some positive comments to make - such as 'comprehensive and continuous evaluation' reduced examination pressure for students and child-centred education was in general beneficial for learning, the teachers primarily viewed the policy as problematic. They identified the following areas, in no particular order, as being of most concern: Continuous and Comprehensive Evaluation (CCE) and no-detention policy (NDP); managing clerical work; and infrastructural deficiencies. The main issues with CCE and NDP were that actual learning was not taking place; teachers found it very difficult to teach the students who were academically behind; CCE and NDP demotivate students from studying; and teachers felt disempowered by NDP to motivate students to study. Particular difficulties the teachers experienced are presented below:

\section{Comprehensive and Continuous Evaluation and no- detention policy}

The teachers reported that actual learning was not taking place because of CCE and NDP, which resulted in a significant proportion of students being academically behind.

These students have little or no academic knowledge or skills and are unable to read, spell or write properly or do basic mathematics, with a few students not being able to write or do any mathematics at all. The teachers were more concerned about NDP than about CCE as a contributing factor to the poor learning outcome.

The teachers interviewed mainly taught the $11^{\text {th }}$ and $12^{\text {th }}$ grades, years that constitute preparation for the 
school-leaving external Board Examinations held at the end of the $12^{\text {th }}$ grade. They found it very difficult to teach the students who are academically behind because they arrive at these grades with little or no knowledge and are below the required academic level or have disparate academic levels. They described the students who are academically behind as being unable to learn and unable to understand examination questions, let alone answer them. The teachers are under pressure to achieve a hundred per cent pass rate and their main concern is that their students pass these high stakes examinations. They reported that a significant proportion of students fail in the higher classes, whereas they would previously have passed.

The teachers essentially oriented their teaching of the segment of students who were academically behind towards assisting them to catch up, prepare for and pass the Board Examinations. They described this as being a significant problem for them, one that involved constant effort and even going as far back as the $6^{\text {th }}$ grade. They employed various remedial strategies which include the following: starting with the basics; trying to teach in an interesting way to make the subject interesting; giving extra time to the students who were behind without putting the students who were doing well at a disadvantage; translating the examination papers, which are in English, word for word to the local language; moving students who were not able to study in English to the Punjabi medium stream to make learning easier for them; providing notes on the textbook and class discussions to simplify the language; teaching the students who were behind how to read and then giving them extra work sheets, checking on their work every day; and going through past examination papers in class line by line.

The teachers reported that both CCE and NDP demotivate students from studying. They attributed this to the students' lack of academic knowledge and skills. Whereas they previously used to be self-motivated to study, the teachers now have to constantly try to motivate students. Some teachers also thought that students would work harder if they knew they would not automatically progress to the next grade.

Some teachers thought that the cumulative point system of CCE as well as a lowered pass mark of thirty-three per cent - because there are other criteria to measure the performance of students - make it easy for students to pass without their having to study. Other comments about CCE were that the cumulative point system encourages students to copy other students' work; the current emphasis on activities with CCE hinders learning because students are just doing one activity or the other and are not developing concepts or the necessary academic foundation; the Internet-based projects in particular are not always age appropriate, which results in little learning.

Teachers reported that they felt NDP disempowered them from motivating students to learn and that they felt powerless and under a lot of pressure, particularly during the examination period. The view of all the teachers was that comprehensive and continuous evaluation was not working. They made the following comments: teachers can no longer be strict with students; the authority and ability of teachers to motivate students are now undermined because students know that they will automatically progress to the next grade; students do not listen to teachers or respect them because they know that they will pass the grade; the only sanction teachers now have is to tell students who do not work that they will not be allowed to sit a test, whereas previously students would have been afraid of failing that test;and discipline and a little strictness benefits students.

\section{Managing clerical work}

The teachers' paperwork and clerical duties have substantially increased, with the result that they are overburdened and time is taken away from learning. The teachers felt overwhelmed at times and thought that paperwork was being given more importance than teaching. They have to make lists of students, fill out scholarship paperwork and administer scholarships, hand out free textbooks for qualifying students, enter marks in the computer system, make report cards, and do extra clerical work. This is mostly done in their free periods and at home, often late at night. Some of this work has to be done in class time, however, and with class sizes of eighty students or more, these activities can take up substantial class time. Teachers found it stressful to have to manage their classes whilst undertaking the various non-teaching tasks and 
felt that the quality of their teaching was being negatively affected because there was very little time for actual teaching. Not all teachers are proficient at using the computer, which adds to their difficulties.

\section{Infrastructural deficiencies}

The main issues the teachers reported were a general lack of facilities, a need for teaching aids and an excessively high teacher-pupil ratio. As with the increase in the clerical work teachers have to perform, infrastructural deficiencies also resulted in time being taken away from learning. As an example, in classrooms that do not have enough furniture, half the class time is wasted getting dhurries (rugs) for the students to sit on, which have to then be folded up and returned to the storage room. Weather conditions also present particular difficulties in summer because of the excessive heat and lack of air conditioning. The result is student absenteeism and teachers having to cope with children fainting or suffering from heatstroke. The teachers also reported that various kinds of teaching facilities were lacking. Since learning and assessment are linked in CCE, lack of these facilities could also impact the teachers' ability to assess according to CCE. The teachers reported the need for more visual aids and audio-visual media; a proper, soundproofed laboratory in which to conduct language testing; science laboratories; projectors for conducting science activities; and a proper art classroom. Some teachers felt that justice was not being done for the students because they lacked time, infrastructure and resources and they were also concerned about the effect of this lack on their teaching.

The teachers also reported various difficulties to do with the high teacher-pupil ratio, which ranged from 60-80 students or above at their schools, although the Science streams typically had substantially fewer students. One difficulty was that teachers could not give students the required individual attention. The teachers also reported that the high teacher-pupil ratio made it difficult to evaluate students' work in accordance with CCE and to check it thoroughly to see where assistance was needed. They also reported that the projectors and teaching aids were insufficient; there was lack of space to move around the classroom; and behaviour management became difficult and they disliked shouting because of the resultant noise.

Consideration of the outcome of these issues enabled the identification of whether or not the child-centred objectives of the policy were being met. These results were then interpreted in relation to the concepts of 'Democracy' and 'Experiential Learning' of the theoretical framework in order to determine how the policy was functioning in relation to the benchmark. The issues the teachers raised also highlighted ways in which their ability to fulfil their new role within the child-centred schema was impacted. This result was then interpreted in relation to the concept of 'Teacher as Facilitator' of the theoretical framework to determine whether or not teachers were meeting the benchmark for this role. The criterion for the assessment of how both the child-centred provisions and the role of teachers were functioning was that the benchmark needed to be fully met in order to be deemed as having satisfied it. The conclusions drawn about how the child-centred education provisions of RTE are functioning are set out below:

\section{The functioning of the child-centred education policy:}

The conclusions drawn from the findings in relation to the benchmark for child-centred education present insights into the functioning of seven of the eight child-centred education provisions of RTE as well as into the functioning of the new ascribed role of the Indian teacher as 'facilitator'.

The delivery of six of the seven RTE provisions for a democratic form of education - provisions (a), (b), (c), (d), (g) and (h) - either fell short of the benchmark or was vulnerable to falling short of it. This was because either the objective or objectives of provisions (b), (c), d), (g) and (h) were not met or because teachers were not delivering the objectives of the provisions or their ability to deliver these might have been negatively impacted. This in turn caused provision (a) to either fall short of the benchmark or to be vulnerable to falling short of it. Therefore the functioning of all six provisions is problematic. The teachers did not provide any insights into the functioning of the remaining provision for a democratic form of education, provision (f). The delivery of provision (e) for experiential learning either fell short of the benchmark or was vulnerable to falling short of 
Table 1: The Child-Centred Education Benchmarks

\begin{tabular}{|c|c|c|c|c|c|c|}
\hline \multirow[b]{2}{*}{ The Issues the Teachers Reported } & \multicolumn{2}{|c|}{$\begin{array}{c}\text { Benchmark for a Democratic } \\
\text { Form of Education }\end{array}$} & \multicolumn{2}{|c|}{$\begin{array}{c}\text { Benchmark for Experiential } \\
\text { Learning }\end{array}$} & \multicolumn{2}{|c|}{$\begin{array}{c}\text { Benchmark for Teacher } \\
\text { as Facilitator }\end{array}$} \\
\hline & $\begin{array}{l}\text { RTE } \\
\text { Provision } \\
\text { Not Met } \\
\end{array}$ & $\begin{array}{l}\text { RTE Provision } \\
\text { Vulnerable }\end{array}$ & $\begin{array}{l}\text { RTE } \\
\text { Provision } \\
\text { Not Met } \\
\end{array}$ & $\begin{array}{l}\text { RTE } \\
\text { Provision } \\
\text { Vulnerable } \\
\end{array}$ & Not Met & Vulnerable \\
\hline NDP/CCE Issues & & & & & & \\
\hline $\begin{array}{l}\text { 1. Actual learning was not taking } \\
\text { place }\end{array}$ & $\begin{array}{l}\text { (a) }(\mathrm{h})(\mathrm{b}) \\
(\mathrm{d})\end{array}$ & & & & $\sqrt{ }$ & \\
\hline $\begin{array}{l}\text { 2. It was very difficult to teach the } \\
\text { students who are academically } \\
\text { behind }\end{array}$ & $\begin{array}{l}\text { (a) (b) (c) } \\
\text { (d) (g) (h) }\end{array}$ & & (e) & & $\sqrt{ }$ & \\
\hline $\begin{array}{l}\text { 3. Continuous and Comprehensive } \\
\text { Evaluation (CCE) and the } \\
\text { No-Detention Policy (NDP) } \\
\text { demotivated students from } \\
\text { studying }\end{array}$ & (a) (h) & (b) (c) (d) & & (e) & & \\
\hline $\begin{array}{l}\text { 4. Teachers felt disempowered by } \\
\text { NDP to motivate students to study }\end{array}$ & & $\begin{array}{l}\text { (a) (b) (c) } \\
\text { (d) (h) }\end{array}$ & & (e) & & $\sqrt{ }$ \\
\hline Managing Clerical Work & & $\begin{array}{l}\text { (a) (b) (c) } \\
\text { (d) (g) (h) }\end{array}$ & & (e) & & $\sqrt{ }$ \\
\hline Infrastructural Deficiencies & & (a) (b) (c) & & (e) & & $\sqrt{ }$ \\
\hline
\end{tabular}

it. The results in relation to the benchmark for the role of 'Teacher as Facilitator' relate to the teachers who were interviewed as the ones who experienced the issues they reported. The teachers fell short of this benchmark or were vulnerable to falling short of it, either because they were not being 'a capable facilitator, who motivates children to construct their own knowledge' or because their ability to do so might be negatively impacted. These conclusions are set out in the table 1 .

Through the findings presented above, this case study makes an original contribution to the literature on the implementation of RTE in various ways. It adds to it by presenting similar findings into the functioning of CCE as a form of assessment. It also provides additional insights into its functioning as well as insights into NDP as an additional dimension of CCE through the interrelationship between the two provisions. This research also extends the literature through its focus on all of the provisions of RTE as well as the new role of the Indian teacher as 'facilitator'; in so doing it makes it explicit that the literature addresses the child-centred aspect of RTE. The research findings present insights into seven of the eight child-centred provisions of RTE and also show that all these elements of the child-centred education policy are interrelated in their functioning. This research also extends the literature through its introduction of a theoretical dimension and the creation of an original theoretical framework for the research conducted.

\section{CONCLUSION}

The literature reviewed as well as this case study indicate that there are problematic aspects with the functioning of RTE's child-centred education provisions. The literature points to difficulties that teachers experience with implementing the RTE provision for continuous assessment. This case study presents similar findings and shows that the 'no-detention policy, the automatic promotion of students to the next grade, also presents significant challenges for teaching and learning. Its findings also show that the functioning of seven out of eight of the child-centred education provisions of RTE as well as the new role of the Indian teacher as 'facilitator' is problematic. More research into RTE's child-centred education provisions, and of varied kinds and scope, is needed.

There are other areas where further research would be beneficial. The amendment to RTE of 2019 referred to at the beginning, after several years of consultation with state governments, has made changes to the 'no-detention policy' and to the 
provision for continuous assessment. It reinstates examinations in the fifth and eight grades of primary school and enables state governments to allow schools to hold back students who fail in either or both grades after retaking the examinations having been given additional instruction. The original clause of RTE stipulated that no student shall be detained in the same class or expelled from school until they complete their elementary education. Students may still not be expelled from school until the completion of elementary education if a state government does not hold back students.

Research is therefore needed into whether and/or how the re-introduction of examinations as a form of assessment in the fifth and eighth grades and detaining students who fail them helps to resolve the above issues that have been identified in the research in relation to student learning, student motivation to learn, teachers' ability to teach and motivate students to learn and assessment according to continuous and comprehensive evaluation.

Through its changes the amendment to RTE has also altered the policy conceptualisation of its provisions as providing a democratic form of education. The system of continuous assessment was intended to remove the 'fear and trauma of failure' engendered by the competitiveness and stress of end-of-year examinations, give students adequate time to develop their learning and understanding, enable the teacher to give students individual attention and to promote the better learning of all. Research is therefore needed to investigate the nature of this alteration and what it means for this conceptualisation of the child-centred education policy. Understanding is also needed of how students, teachers and learning may be affected by the consequent re-introduction of year-end examination stress and how the intended benefits of continuous assessment may be affected.

\section{REFERENCES}

Ashita, R. 2013. Beyond Testing and Grading: Using Assessment to Improve Teaching-Learning. Research Journal of Educational Sciences, 1(1): 2-7.

Basu, S. and Debnath, D. 2016. A Survey on Continuous and Comprehensive Evaluation System Introduced by West Bengal Board of Secondary Education Among the Students, Teachers, Guardians of Hooghly District of West Bengal. International Journal of Informative and Futuristic Research, 3(8): 3158-3166.
Government of India. 2009. The Right of Children to Free and Compulsory Education Act. L. D. Ministry of Law and Justice. New Delhi.

Government of India. 2011. Sarva Shiksha Abhiyan: Framework for Implementation, Ministry of Human Resource and Development, Department of School Education and Literacy, New Delhi.

Kothari, R.G. and Thomas, M.V. 2012. A Study on Implementation of Continuous and Comprehensive Evaluation in Upper Primary Schools of Kerala. MIER Journal of Educational Studies, Trends E Practices, 2(2).

Kumar, Y.M. and Kumar, K.S. 2015. A study on awareness of CCE among secondary school teachers. Scholarly Research Journal for Interdisciplinary Studies, 3(XVII).

Mishra, S. and Mallik, P. 2014. Perception of Teachers, Parents and Students about Continuous and Comprehensive Evaluation at Elementary School Level in Odisha. Pedagogy of Learning, 2(1): 19-28.

Panda, B.N. 2014. Status of Continuous and Comprehensive Evaluation at Elementary Stage. Journal of All India Association for Educational Research, 26(1).

Pazhanimurugan, S.R., Sivakumar, R. and Benjamin, E.W. 2015. Teachers' Attitude Towards Continuous and Comprehensive Evaluation on Secondary Schools. Indian Journal of Applied Research, 5(1).

Saluja, A. 2016. New Dimensions in Evaluation: Teachers' Perspective on CCE and its Implementation. International Journal of Science and Technology and Management, 5(8).

Sarin, Meera Nath. 2015. Quality education for all? A case study of a New Delhi government school. Policy Futures in Education, 13(3): 360-374.

Seidman, I. 2006. Interviewing as Qualitative Research: a Guide for Researchers in Education and the Social Sciences. New York: Teachers College Press.

Sethi, C. and Muddgal, A. 2017. A Study of Implementation and Challenges of Continuous and Comprehensive Evaluation as Mentioned in Right to Education Act, 2009 Among Municipal Corporation Primary School teachers of Delhi. Scholarly Research Journal for Interdisciplinary Studies, 4(30): 4695-4700.

Silverman, D. 2006. Interpreting Qualitative Data: Methods for Analyzing Talk, Text and Interaction. London: Sage Publications Inc.

Singhal, P. 2012. Continuous and Comprehensive Evaluation: A Study of Teachers' Perception. Delhi Business Review, 13(1).

Srinivasan, M.V. 2015. Centralised Evaluation Practices: an Ethnographic Account of Continuous and Comprehensive Evaluation in a Government Residential School in India. Contemporary Education Dialogue, 12(1): 59-86.

Stake, R.E. 1995. The Art of Case Study Research. California: Sage Publications, Inc.

Stake, R.E. 2005. Qualitative Case Studies. In: Denzin N.K. and Lincoln, Y.S. (eds) The Sage Handbook of Qualitative Research. California: Sage Publications, Inc., pp. 443-466. 
Thakur, U.R. 2016. A study on the perception of the students and teachers towards continuous and comprehensive evaluation at secondary school level under Dibrugarh district of Assam. International Journal of Humanities $\mathcal{E}$ Social Science Studies, 2(4).
UNESCO. 2015. Incheon Declaration and Framework for Action for the Implementation of Sustainable Development Goal 4, Republic of Korea, May. 